\title{
Investigating the performance of shunt FACTS for the operation of induction motors under different voltage sag conditions
}

\begin{abstract}
Shunt FACTS devices are prevalent in industrial application of induction motors. These equipments are effective to compensate disturbances and increase motor speeding up. In this study an assessment study between two different shunt FACTS (SVC and STATCOM) installed on terminals of motor is done. A conventional PI controller is used to control the thyristor firing angle of SVC or phase angle of STATCOM. A pole placement method is applied to specify the perfect gain settings of the controllers. The results of simulations display that STATCOM has better response over SVC for improving dynamic behavior of induction motor under ideal supply conditions. Power quality problem that influence the dynamic behavior of induction motor, include non ideal conditions such as harmonics, interruptions, voltage unbalance and voltage sags. Whereas voltage sags is one of the main cause of disturbances in distribution systems, the performances of the induction motor under symmetrical and unsymmetrical voltage sags are investigated in this study. The results prove that STATCOM is more effectual than SVC for reduction of transients and refinement the voltage profile.
\end{abstract}

Keyword: Induction motors; SVC; STATCOM; Voltage sag 